\title{
Analisis Kemampuan Pemahaman Konsep Pertidaksamaan Linear Satu Variabel Ditinjau Dari Gaya Kognitif Siswa
}

\author{
Nisa Amaliah ${ }^{1}$, Wahyuddin ${ }^{2}$, Andi Quraisy ${ }^{3}$ \\ 1,2,3Pendidikan Matematika, FKIP, Universitas Muhammadiyah Makassar, Makassar, Indonesia \\ Email: ${ }^{1 *}$ nisa@ student.unismuh.ac.id, ${ }^{2 *}$ wahyu@ unismuh.ac.id, ${ }^{3 *}$ andiquraisy@unismuh.ac.id
}

\section{Informasi Artikel \\ Diterima : 11-12-2021 \\ Revisi : 16-12-2021 \\ Diterbitkan : 20-01-2022}

Keywords:

Ability to Understand Concepts Cognitive Styles

One Variable Linear Inequality

\begin{abstract}
The main objective is to determine the students' conceptual understanding ability in terms of cognitive style. The type of research used is a qualitative research conducted at UPT SPF SMPN 49 Makassar. Research subjects as many as 4 people who were selected each 2 FD and 2 FI. The data collection technique used GEFT test, concept understanding ability test and interview. The instruments used were first validated by two experts. The data collected were analyzed by descriptive and qualitative analysis through the stages that include data collection, data reduction, data presentation, and drawing conclusions. Test the validity of the data using triangulation techniques. The results of this study conclude that there are differences in the ability to understand concepts of students with FI and FD cognitive styles with the description: (1) the ability to understand concepts of students with field dependent cognitive style (FD) fulfills the three indicators of giving examples and not examples of a concept, presenting concepts in various ways. form of mathematical representation, and apply concepts into problem solving, (2) The ability to understand concepts of students with field independent cognitive style (FI) fulfills the four indicators restating a concept, giving examples and not examples of a concept, presenting concepts in various forms of mathematical representation, and apply concepts to problem solving.
\end{abstract}

\begin{abstract}
Abstrak
Tujuan penelitian ini untuk mengetahui kemampuan pemahaman konsep siswa ditinjau dari gaya kognitif. Jenis penelitian yang digunakan adalah penelitian kualitatif yang dilaksanakan di UPT SPF SMPN 49 Makassar. Subjek penelitian sebanyak 4 orang yang dipilih masing-masing 2 FD dan 2 FI. Teknik pengumpulan data menggunakan tes GEFT, tes kemampuan pemahaman konsep dan wawancara. Instrumen yang digunakan terlebih dahulu divalidasi oleh dua orang ahli. Data yang terkumpul dianalisis dengan analisis deskriptif dan kualitatif melalui tahap-tahap yang meliputi pengumpulan data, reduksi data, penyajian data, dan penarikan kesimpulan. Uji keabsahan data menggunakan triangulasi teknik. Hasil penelitian ini menyimpulkan bahwa terdapat perbedaan kemampuan pemahaman konsep siswa gaya kognitif FI dan FD dengan uraian: (1) kemampuan pemahaman konsep siswa dengan gaya kognitif field dependent (FD) memenuhi ketiga indikator memberi contoh dan bukan contoh dari suatu konsep, menyajikan konsep dalam berbagai bentuk representasi matematika, dan mengaplikasikan konsep kedalam pemecahan masalah, (2) Kemampuan pemahaman konsep siswa dengan gaya kognitif field independent (FI) memenuhi keempat indikator menyatakan ulang sebuah konsep, memberi contoh dan bukan contoh dari suatu konsep, menyajikan konsep dalam berbagai bentuk representasi matematika, dan mengaplikasikan konsep kedalam pemecahan masalah.
\end{abstract}

Kata Kunci: Kemampuan Pemahaman Konsep, Gaya Kognitif, Pertidaksamaan Linear Satu Variabel 


\section{PENDAHULUAN}

Matematika merupakan salah satu ilmu pengetahuan yang berperan penting dalam perkembangan ilmu pengetahuan dan teknologi, baik dalam membantu penerapan-penerapan ilmu lain maupun dalam pengembangan matematika itu sendiri. Menurut Purwanti et al., (2016) bahwa matematika juga termasuk salah satu mata pelajaran yang menjadi standar untuk diujikan ketika akan melanjutkan pendidikan kejenjang yang lebih tinggi dan merupakan cabang ilmu yang bermanfaat dalam bersosialisasi di masyarakat.

Belajar matematika harus dimulai dengan memahami materi yang diajarkan terlebih dahulu. Kemudian dapat diaplikasikan ke dalam kehidupan sehari-hari. Mengingat pentingnya memahami suatu materi dalam pembelajaran matematika, maka perlu ditingkatkan pemahaman konsep sejak dini [2]. Pentingnya memiliki pemahaman konseptual juga terdapat dalam tujuan pembelajaran matematika di tingkat sekolah menengah pertama (SMP) baik pada kurikulum 2006 maupun kurikulum 2013, yaitu agar siswa memahami konsep matematika, menjelaskan keterkaitan antar konsep, dan menggunakan konsep secara luwes, akurat, efesien dan tepat dalam pemecahan masalah.

Salah satu poin penting dalam pembelajaran matematika adalah pemahaman konsep. Kilpatrick menyatakan bahwa "conceptual understanding is comperehension of mathematical concepts, operations, and relations" yang berarti pemahaman konseptual adalah menguasai konsep, operasi, dan relasi matematis [3]. Siswa yang memiliki pemahaman konsep lebih mudah mengingat dan menyimpan apa yang telah dipelajari [4]. Oleh karena itu, pemahaman konsep pada siswa perlu dikembangkan.

Pemilikan pemahaman konsep sangat berperan penting untuk mengukur pengetahuan siswa terhadap suatu materi. Aryadi \& Yanti (2017) mengatakan bahwa pemahaman terhadap konsep-konsep matematika merupakan modal dasar dalam menguasai pelajaran matematika. Siswa yang memahami konsep akan bisa menjelaskan suatu materi pelajaran dengan kalimatnya sendiri. Dengan kemampuan siswa dalam menjelaskan atau mendefinisikan, maka siswa tersebut telah paham terhadap konsep atau prinsip dari suatu pelajaran meskipun susunan kalimat penjelasan yang diberikan tidak sama dengan konsep yang diberikan tetapi mempunyai makna yang sama. Siswa terlebih dahulu wajib memahami konsep agar mampu menyelesaikan soal-soal dan dapat mengaplikasikannya dalam kehidupan sehari-hari.

Berdasarkan uraian sebelumnya sehingga pemahaman konsep penting dikuasai oleh siswa. Namun faktanya salah satu penyebab gagalnya siswa dalam belajar matematika adalah siswa tidak memahami konsep - konsep matematika atau siswa salah dalam memahami konsep matematika. Terdapat beberapa permasalahan yang berkaitan dengan pemahaman konsep seperti yang dikemukakan Dewanti et al., (2018) siswa masih melakukan kesalahan dalam menjawab soal yang ditanyakan mengenai pemahaman konsep dari suatu materi.

Rendahnya pemahaman konsep matematis siswa juga terjadi di UPT SPF SMPN 49 Makassar dilihat dari salah satu contoh siswa dalam mengerjakan soal. Dari hasil jawaban siswa dilihat bahwa pemahaman konseptual siswa tersebut masih belum sesuai dengan yang diharapkan, siswa tersebut belum mampu menjawab soal dengan benar yaitu siswa tersebut belum bisa menentukan sifat - sifat pertidaksamaan dan memberikan alasan dari jawaban yang diberikan.

Selain pemahaman konsep, gaya kognitif juga merupakan salah satu variabel kondisi belajar yang menjadi pertimbangan dalam merancang pembelajaran. Brown menjelaskan bahwa gaya kognitif merupakan karakteristik seseorang dalam menerima, menganalisis, dan merespon suatu tindakan kognitif yang diberikan. Gaya kognitif pada aspek psikologis ini terdiri dari gaya kognitif field independen dan gaya kognitif field dependent [7].

Gaya kognitif field independent (FI) adalah seseorang dengan tingkat kemandirian yang tinggi dalam memproses informasi, mengingat, berpikir dan memecahkan masalah yang cenderung memilih belajar secara individu/mandiri. Sedangkan gaya kognitif field dependent (FD) adalah seseorang yang dalam memproses informasi, mengingat, berpikir dan memecahkan masalah yang cenderung memilih belajar secara kelompok dan sangat bergantung pada sumber informasi dari guru [3].

Beberapa hasil penelitian yang relevan diantaranya yaitu penelitian [8] dengan hasil penelitian menyimpulkan bahwa pemahaman konsep geometri, subjek yang memiliki gaya kognitif field dependent hanya memenuhi 4 indikator yaitu: (1) menyatakan secara verbal konsep yang dipelajari, (2) mengklasifikasikan konsep berdasarkan dipenuhi atau tidaknya persyaratan, (3) menerapkan konsep 
secara algoritma, dan (4) menerapkan konsep dalam berbagai macam bentuk representasi. Indikator yang belum dapat SFD lakukan adalah mengaitkan berbagai konsep (internal dan eksternal matematika). Pemahaman konsep geometri subjek field independent dapat memenuhi ke lima indikator dari pemahaman konsep yaitu: (1) menyatakan secara verbal konsep yang dipelajari, (2) mengklasifikasikan konsep berdasarkan dipenuhi atau tidaknya persyaratan, (3) menerapkan konsep secara algoritma, (4) menerapkan konsep dalam berbagai macam bentuk representasi, dan (5) mengaitkan berbagai konsep (internal dan eksternal matematika). Demikian juga temuan penelitian Suliswanto et al., (2020) bahwa bahwa siswa dengan gaya kognitif field independent mendefinisikan pengertian sistem persamaan linier tiga variabel dengan menggunakan bahasanya sendiri dan tidak terpaku dengan notasi yang ada. Siswa juga bisa membedakan contoh dan bukan contoh dari sistem persamaan linier tiga variabel dan bisa menyelesaikan masalah SPLTV secara analitis. Sedangkan siswa yang bergaya kognitif field dependent mendefinisikan pengertian sistem persamaan linier tiga variabel dengan bahasa yang masih terpaku dengan notasi sistem persamaan linier tiga variabel yang telah diterima. Selain itu, siswa juga bisa membedakan contoh dari sistem persamaan linier tiga variabel dan kurang bisa menyelesaikan masalah SPLTV secara analitis.

Berbeda dengan beberapa penelitian terdahulu sebelumnya seperti (Alvarado-Karste \& Guzmán, 2020; Jainuddin \& Sirajuddin, 2020; Syaiful et al., 2020), dalam penelitian ini fokus pada bagaimana menganlisis kemampuan pemahaman konsep siswa ditinjau dari gaya kognitif dan akan dikkususkan pada materi pertidaksamaan linear satu variabel. Penelitian terkait tema ini sangat penting untuk dilakukan karena dapat memerikan informasi tentang bagaiman kemampuan pemahaman konsep siswa jika ditinjau dari gaya kognitifnya. Sehingga berdasarkan hasil penelitian yang diperoleh dapat ditawarkan suatu solusi dalam meningkatkan kemampuan pemahaman konsep matematika siswa. Selain itu, temuan penelitian yang diperoleh dapat menjadi dasar penetian pengambangan dalam hal pemahaman konsep matematika. Hasil penelitian ini juga dapat digunakan oleh guru sebagai dasar dalam pemilihan strategi dan metode dalam meningkatkan kemampuan siswa dalam pemahaman konsep matematika. Oleh karena iti, maka tujuan utama penelitian ini adalah untuk menganalisis dan mendeskripsikan kemampuan pemahaman konsep pertidaksamaan linear satu variabel ditinjau dari gaya kognitif siswa

\section{METODE PENELITIAN}

Jenis penelitian adalah penelitian kualitatif pendekatan deskriptif tang dilaksanakan di UPT SPF SMPN 49 Makassar, Sulawesi Selatan pada semester ganjil Tahun Akademik 2021-2021. Subjek dalam penelitian sebanyak 4 orang yang dipilih masing-masing 2 FD dan 2 FI. Teknik pengumpulan data menggunakan tes GIFT, tes pemahaman konsep, dan wawancara. Instrumen yang digunakan terlebih dahulu divalidasi oleh dua orang ahli. Data yang terkumpul selanjutnya dianalisis dengan analisis deskriptif dan analisis data kualitatif melalui proses reduksi data, penyajian data dan penarikan kesimpulan.

\section{HASIL DAN PEMBAHASAN}

Pengumpulan data pada penelitian ini dilakukan melalui tes GEFT, tes kemampuan pemahaman konsep, dan wawancara. Tes GEFT digunakan untuk penentuan subjek, selanjutnya dipilih 4 orang siswa yang dijadikan subjek penelitian. Dari hasil tes GEFT terdapat 25 orang yang memiliki kategori FD, 2 orang yang memiliki kategori FI. Selanjutnya dipilih 4 orang subjek yang masing-masing 2 FD dan 2 FI yang akan diberikan kode berturut-turut yaitu S1FD, S2FD, S1FI, S2FI.

Berikut daftar siswa yang telah dipilih sebagai subjek dari penelitian ini:

Tabel 1. Subjek Penelitian

\begin{tabular}{lccc}
\hline No. & Inisial Siswa & Gaya Kognitif & Kode Subjek \\
\hline 1. & ALPS & $F D$ & S1FD \\
2. & NRS & $F D$ & S2FD \\
3. & CF & $F I$ & S1FI \\
4. & SAP & $F I$ & S2FI \\
\hline
\end{tabular}

Proses selanjutnya yaitu kembali memberikan tes kemampuan pemahaman konsep pertidaksamaan linear satu variabel dengan jumlah soal 4 nomor kepada 4 subjek berbentuk essai. Adapun hasil tes kemampuan pemahaman konsep siswa sebagai berikut: 


\begin{tabular}{lcccc}
\hline \multicolumn{1}{c}{ Indikator } & S1FD & S2FD & S1FI & S2FI \\
\hline $\begin{array}{l}\text { Kemampuan menyatakan ulang } \\
\text { sebuah konsep }\end{array}$ & $\times$ & $\sqrt{ }$ & $\sqrt{ }$ & $\sqrt{ }$ \\
$\begin{array}{l}\text { Kemampuan memberi contoh dan } \\
\text { bukan contoh dari suatu konsep }\end{array}$ & $\sqrt{ }$ & $\sqrt{ }$ & $\sqrt{ }$ & $\sqrt{ }$ \\
$\begin{array}{l}\text { Kemampuan menyajikan konsep } \\
\text { dalam berbagai bentuk representasi }\end{array}$ & $\sqrt{ }$ & $\sqrt{ }$ & $\sqrt{ }$ & $\sqrt{ }$ \\
$\begin{array}{l}\text { matematika } \\
\text { Kemampuan mengaplikasikan }\end{array}$ & $\sqrt{ }$ & $\sqrt{ }$ & $\sqrt{ }$ & $\sqrt{ }$ \\
\hline
\end{tabular}

Berdasarkan hasil analisis data pada soal nomor 1 indikator 1 menyatakan ulang sebuah konsep pertidaksamaan linear satu variabel, subjek S1FD dapat menjawab pertanyaan dengan benar, menjelaskan pengertian pertidaksamaan linear satu variabel menggunakan bahasanya sendiri, dan dapat menuliskan bentuk umum dari pertidaksamaan linear satu variabel. Sedangkan subjek S2FD tidak mampu memenuhi indikator 1 karena tidak dapat menjelaskan pengertian pertidaksamaan linear satu variabel dengan benar dan salah dalam menuliskan bentuk umum dari pertidaksamaan linear satu variabel. Sehingga dapat di simpulkan bahwa siswa dengan gaya kognitif field dependent tidak mampu memenuhi indikator menyatakan ulang sebuah konsep.

Pada indikator 2 terkait kemampuan memberi contoh dan bukan contoh pertidaksamaan linear satu variabel soal nomor 2, kedua subjek FD dapat menuliskan contoh dan bukan contoh pertidaksamaan linear satu variabel dengan benar. Sehingga dapat disimpulkan siswa dengan gaya kognitif field dependent mampu memenuhi indikator kemampuan memberi contoh dan bukan contoh dari suatu konsep. Selanjutnya, pada indikator 3 terkait kemampuan menyajikan konsep dalam berbagai bentuk representasi matematika pada soal nomor 3, kedua subjek FD dapat menuliskan bentuk matematika dari soal yang diberikan dengan benar. Sehingga dapat disimpulkan subjek FD mampu memenuhi indikator menyajikan konsep dalam berbagai bentuk representasi matematika. Demikian halnya pada indikator 4 kemampuan mengaplikasikan konsep kedalam pemecahan masalah pada soal nomor 4, kedua subjek FD menyelesaikan soal pertidaksamaan linear satu variabel dengan langkah-langkah yang tepat. Sehingga dapat disimpulkan subjek FD memenuhi indikator kemampuan mengaplikasikan konsep kedalam pemecahan masalah.

Berdasarkan pemaparan tersebut dapat disimpulkan bahwa kemampuan pemahaman konsep siswa dengan gaya kognitif field dependent (FD) hanya memenuhi tiga indikator memberi contoh dan bukan contoh dari suatu konsep, menyajikan konsep dalam berbagai bentuk representasi matematika, dan mengaplikasikan konsep kedalam pemecahan masalah. Dan tidak memenuhi satu indikator yaitu indikator menyatakan ulang sebuah konsep.

Lebih lanjut, pada soal nomor 1 indikator 1 menyatakan ulang sebuah konsep pertidaksamaan linear satu variabel, kedua subjek FI dapat menjawab pertanyaan dengan benar, menjelaskan pengertian pertidaksamaan linear satu variabel menggunakan bahasanya sendiri, dan dapat menuliskan bentuk umum dari pertidaksamaan linear satu variabel. Sehingga dapat di simpulkan bahwa siswa dengan gaya kognitif field independent mampu memenuhi indikator menyatakan ulang sebuah konsep. Pada indikator 2 terkait kemampuan memberi contoh dan bukan contoh pertidaksamaan linear satu variabel soal nomor 2, kedua subjek FI dapat menuliskan contoh dan bukan contoh pertidaksamaan linear satu variabel dengan benar. Sehingga dapat disimpulkan siswa dengan gaya kognitif field dependent mampu memenuhi indikator kemampuan memberi contoh dan bukan contoh dari suatu konsep.

Selanjutnya, pada indikator 3 terkait kemampuan menyajikan konsep dalam berbagai bentuk representasi matematika pada soal nomor 3, kedua subjek FI dapat menuliskan bentuk matematika dari soal yang diberikan dengan benar. Sehingga dapat disimpulkan subjek FI mampu memenuhi indikator menyajikan konsep dalam berbagai bentuk representasi matematika. Pada indikator 4 kemampuan mengaplikasikan konsep kedalam pemecahan masalah pada soal nomor 4, kedua subjek FI menyelesaikan soal pertidaksamaan linear satu variabel dengan langkah-langkah yang tepat. Sehingga dapat disimpulkan subjek FI memenuhi indikator kemampuan mengaplikasikan konsep kedalam pemecahan masalah.

Berdasarkan pemaparan diatas dapat disimpulkan bahwa kemampuan pemahaman konsep siswa dengan gaya kognitif field independent (FI) memenuhi semua indikator menyatakan ulang sebuah konsep, memberi contoh dan bukan contoh dari suatu konsep, menyajikan konsep dalam berbagai bentuk representasi matematika, dan mengaplikasikan konsep kedalam pemecahan masalah. 
Oleh katena itu, temuan penelitian ini mengunkapkan bahwa kemampuan pemahaman konsep siswa ditinjau dari gaya kognitif field independent lebih tinggi dari pada siswa dengan gaya kognitif field dependent. Hal ini sejalan dengan hasil penelitian (Janah, 2020; De Keersmaecker et al., 2020; Son, 2020) yang mengatakan bahwa siswa yang memiliki gaya kognitif FI mampu melakukan proses berpikir pemecahaan masalah dengan baik dibandingkan dengan individu dengan gaya kognitif FD. Hasil penelitian yang relevan yaitu temuan Setiawati et al., (2019) dan Tsurayya \& Ningrum, (2021) bahwa pemahaman konseptual siswa dikaji dari gaya kognitif dengan kategori field independent lebih baik dari pada siswa dengan kategori field dependent.

\section{KESIMPULAN}

Berdasarkan hasil penelitian dan pembahasan maka diperoleh simpulan bahwa kemampuan pemahaman konsep gaya kognitif field independent lebih tinggi dari pada siswa dengan gaya kognitif field dependent, dimana kemampuan pemahaman konsep siswa dengan gaya kognitif field dependent (FD) memenuhi ketiga indikator memberi contoh dan bukan contoh dari suatu konsep, menyajikan konsep dalam berbagai bentuk representasi matematika, dan mengaplikasikan konsep kedalam pemecahan masalah. Dan tidak memenuhi satu indikator yaitu indikator menyatakan ulang sebuah konsep. Sedangkan kemampuan pemahaman konsep siswa yang memiliki gaya kognitif field independent (FI) memenuhi keempat indikator menyatakan ulang sebuah konsep, memberi contoh dan bukan contoh dari suatu konsep, menyajikan konsep dalam berbagai bentuk representasi matematika, dan mengaplikasikan konsep kedalam pemecahan masalah. Sehingga dalam penelitian ini disarankan kepada guru agar dalam pembelajaran matematika perlu diidentifikasi gaya kognitif siswa serta memberikan model, metode, dan strategi pembelajaran yang sesuai dengan gaya kognitif dan karakteristik siswa, khususnya dalam pembelajaran matematika.

\section{REFERENCES}

[1] R. D. Purwanti, D. D. Pratiwi, and A. Rinaldi, "Pengaruh pembelajaran berbatuan geogebra terhadap pemahaman konsep matematis ditinjau dari gaya kognitif," Al-Jabar: Jurnal Pendidikan Matematika, vol. 7, no. 1, pp. 115-122, 2016.

[2] D. Trapsilasiwi, K. F. Jhahro, and T. B. Setiawan, "Pemahaman Konsep Siswa Pada Pemecahan Masalah Soal Geometri Pokok Bahasan Segiempat Ditinjau Dari Gaya Kognitif Reflektif-Impulsif Siswa," Kadikma, vol. 9, no. 1, pp. 116-122, 2018.

[3] D. Setiawati, S. Sugiatno, and A. Nursangaji, "Pemahaman Konseptual Siswa Dikaji Dari Gaya Kognitif Dalam Materi Pertidaksamaan Linear Satu Variabel di SMP," Jurnal Pendidikan dan Pembelajaran Khatulistiwa, vol. 8, no. 9, 2019.

[4] Wahyuddin, S. Satriani, Ernawati, and Nursakiah, "Analysis of Troubleshooting Ability Reviewed From Student Cognitive Style," IJMTT, vol. 66, no. 2, pp. 155-162, Feb. 2020, doi: 10.14445/22315373/IJMTT-V66I2P519.

[5] Z. Aryadi and S. Yanti, "Pemahaman Konseptual Siswa pada Materi Pertidaksamaan Linear Satu Variabel di Sekolah Menengah Pertama," Pontianak: Untan. Diakses, vol. 17, 2017.

[6] N. A. Dewanti, P. Sujatmiko, and G. Pramesti, "Analisis Pemahaman Konsep Matematika Siswa Dalam Menyelesaikan Soal Faktorisasi Suku Aljabar Berdasarkan Kesulitan Belajar Faktor Intelektual Siswa Pada Kelas Viii B Smp N 8 Surakarta Tahun Ajaran 2016/2017,” Phenomenon: Jurnal Pendidikan MIPA, vol. 8, no. 1, pp. 26-35, 2018.

[7] H. Ulya, "Hubungan gaya kognitif dengan kemampuan pemecahan masalah matematika siswa," Jurnal konseling GUSJIGANG, vol. 1, no. 2, 2015.

[8] M. Ma'rufi, R. Fabrika Pasandaran, and A. Yogi, "Pemahaman konsep geometri mahasiswa berdasarkan gaya kognitif mahasiswa," Pemahaman Konsep Geometri Mahasiswa Berdasarkan Gaya Kognitif Mahasiswa, vol. 1, no. 2, pp. 56-67, 2018.

[9] D. Suliswanto, D. Juniati, and P. Wijayanti, "Profil Pemahaman Konsep Siswa pada Materi Sistem Persamaan Linier Tiga Variabel Ditinjau dari Gaya Kognitif," Jurnal Didaktik Matematika, vol. 7 , no. 2, pp. 156-170, 2020.

[10] D. Alvarado-Karste and F. Guzmán, "The effect of brand identity-cognitive style fit and social influence on consumer-based brand equity," Journal of Product \& Brand Management, 2020.

[11] J. Jainuddin and S. Sirajuddin, "Pengaruh Minat dan Kedisiplinan Siswa dengan Gaya Kognitif Field Indefendent terhadap Hasil Belajar Matematika Siswa SMK Farmasi Yamasi Makassar," Delta-Pi: Jurnal Matematika dan Pendidikan Matematika, vol. 9, no. 2, 2020. 
[12] S. Syaiful, S. Aprillya, and E. Anggraeni, "Pengaruh strategi pembelajaran everyone is a teacher here (ETH) ditinjau dari gaya kognitif terhadap pemahaman konsep matematika," Jurnal Gantang, vol. 5, no. 1, pp. 51-59, 2020.

[13] S. R. Janah, "Kemampuan Berpikir Kritis Matematis Ditinjau Dari Gaya Kognitif dan IQ Pada Model Discovery Learning Berpendekatan SPUR," PhD Thesis, Universitas Negeri Semarang, 2020.

[14] J. De Keersmaecker et al., "Investigating the robustness of the illusory truth effect across individual differences in cognitive ability, need for cognitive closure, and cognitive style," Personality and Social Psychology Bulletin, vol. 46, no. 2, pp. 204-215, 2020.

[15] A. L. Son, "Students' Mathematical Problem-Solving Ability Based on Teaching Models Intervention and Cognitive Style.," Journal on Mathematics Education, vol. 11, no. 2, pp. 209-222, 2020.

[16] A. Tsurayya and N. K. Ningrum, "Analisis Kemampuan Pemahaman Konsep Mahasiswa dalam Menyelesaikan Soal Persamaan Diferensial Ditinjau dari Gaya Kognitif," Jurnal Cendekia: Jurnal Pendidikan Matematika, vol. 5, no. 3, pp. 2385-2397, 2021. 